\section{References}

${ }^{1}$ Working Party on the Prevention of Early Neonatal Mortality and Morbidity. Report. London: Department of Health and Social Security : 1974.

2 Social Services Committee. Second report. Perinatal and neonatal mortality. Vol 1. London: HMSO, 1980:129-30.

${ }^{3}$ Chalmers I, McIlwaine G, eds. Perinatal audit and surveillance. Proceedings of the 8th study group of the Royal College of Obstetricians and Gynaecologists. London: Royal College of Obstetrics and Gynaecology, 1980.

4 Anonymous. Inquiries into perinatal and later childhood deaths [Editorial]. Lancet 1983;ii:83-4.

${ }^{5}$ World Health Organisation. International classification of diseases. 9th revision. Vol 1. London: HMSO, 1977:765.

${ }^{6}$ Baird D, Thomson AM. The survey perinatal deaths reclassified by special clinico-pathological assessment. In: Butler NR, Alberman ED, eds. Perinatal problems. Edinburgh: Churchill Livingstone, 1969: 200-10.

${ }^{7}$ Bound JP, Butler NR, Spector WG. Classification and causes of perinatal mortality. Br Med f 1956;ii:1191-6.

8 Butler NR, Bonham DG. Perinatal mortality. Edinburgh: Churchill Livingstone, 1963:186-200.

${ }^{9}$ Butler NR, Bonham DG. Perinatal mortality. Edinburgh: Churchill Livingstone, 1963:204.
10 Wigglesworth JS. Monitoring perinatal mortality-a pathophysiological approach. Lancet 1980;ii:684-5.

11 Chamberlain R, Chamberlain G, Howlett B, Claireaux A. British births 1970. Vol 1. London: Heinemann, 1975:235-53.

12 Butler NR, Alberman ED. Perinatal problems. Edinburgh: Churchill Livingstone, 1969:293.

13 Office of Population Censuses and Surveys. Congenital malformation statistics. Notifications 1971-80. London: HMSO, 1983. (Series MB3, No 1.)

14 Committee on Perinatal Mortality and Morbidity of the International Federation of Gynaecology and Obstetrics. Report. International Federation of Gynaecology and Obstetrics, 1982.

15 Neligan G, Prudham D, Steiner $H$. The formative years. Oxford: Oxford University Press, 1974:68.

16 Edouard L, Alberman E. National trends in the certified causes of perinatal mortality 1968 to 1978 . Br 7 Obstet Gynaecol $1980 ; 87: 833-8$.

17 Thomson AM, Barron SL. A standard maternity information system. In: Chalmers I, McIlwaine G, eds. Perinatal audit and surveillance. London: Royal College of Obstetricians and Gynaecologists, 1980: 79-92.

18 Mutch L, Elbourne D. Standard national perinatal data: a suggested common core of tabulations. Community Med 1983;5:251-9.

(Accepted 15 March 1984)

\title{
Comparison of single and multichannel cystometry in diagnosing bladder instability
}

\author{
J R SUTHERST, M C BROWN
}

\begin{abstract}
The abilities of single channel cystometry and standard multichannel cystometry to diagnose bladder instability were compared in 100 women taking part in a single blind crossover trial. In 93 of the women both tests yielded the same result. The single channel system detected every case of detrusor instability but in seven women suggested detrusor contractions that were not evident on multichannel cystometry. These were probably due to changes in abdominal pressure.

It is concluded that single channel cystometry when used in conjunction with simple urethral tests can provide most of the information that is obtained in specialist centres investigating bladder function.
\end{abstract}

\section{Introduction}

A patient with detrusor instability cannot inhibit the abnormal detrusor contractions caused by either filling of the bladder or provocations such as changes of posture and coughing. The reported prevalence of detrusor instability in women with incontinence varies from $8.7 \%{ }^{1}$ to $63 \%^{2}$; the higher estimates are probably associated with the type of patient referred to specialist centres. None the less, detrusor instability is a major cause of incontinence in women and must be diagnosed accurately so that inappropriate surgery is not done. Incontinence

Royal Liverpool Hospital, Liverpool L7 8XP

J R SUTHERST, MD, FRCOG, reader, department of obstetrics and gynaecology

M C BROWN, BsC, PHD, principal physicist, bioengineering and medical physics unit

Correspondence to: $\mathrm{Mr}$ J R Sutherst. due to detrusor instability responds poorly to surgery, and conservative methods of treatment should always be tried first. ${ }^{3}$ Bates et al found that $58(71.5 \%)$ of 81 patients who had symptoms of incontinence after repair operations had unstable bladders - that is, detrusor instability. ${ }^{4}$ Arnold et al found an incidence of instability of $67 \%$ in women who had had previous surgery compared with an incidence of $48 \%$ in women who had not. ${ }^{5}$

Cystometry is used to study the relation between bladder pressure and volume. Single channel cystometry has been used to study bladder function for over 100 years $^{6}$ but in many centres is now regarded as being insufficiently sensitive to record accurately true changes in detrusor pressures. "Subtracted cystometry" is used instead, in which abdominal pressure (measured via a rectal catheter) is electronically subtracted from total bladder pressure (measured via the bladder catheter) to give a recording of true detrusor pressure. Only in this way can artefacts due, for example, to variations in abdominal pressure be eliminated. The apparatus for single channel cystometry is simple and cheap whereas the multichannel apparatus needed for subtracted cystometry is complicated and expensive.

\section{Patients and methods}

We studied 100 women aged from 22 to 78 (mean 47) years attending an incontinence clinic for evaluation of their symptoms before treatment. All patients underwent both single and multichannel supine and erect cystometry with isotonic saline at $37^{\circ} \mathrm{C}$ infused at $50 \mathrm{ml} / \mathrm{min}$ (medium fill cystometry). (All methods, definitions, and units used in this study, except where specifically noted, conform to the standards proposed by the International Continence Society. ${ }^{8}$ ) In each case provocative tests were introduced when the patient was standing up. These included coughing and heel bouncing. Both types of cystometry were done on the same day according to a single blind crossover programme. Fifty patients were randomly allocated to undergo single channel cystometry first and 50 to undergo multichannel cystometry first. 
The single channel apparatus used was Cystomat (Edwin Burgess, Princes Risborough, Buckinghamshire), which is a sterile disposable device with a drip chamber and an inlet tube connected to a Foley catheter in the patient's bladder. The Foley catheter connects via a $\mathrm{Y}$ piece to the ascending limb of an inverted $\mathrm{U}$ tube manometer provided with a centimetre scale and positioned with its top $60-80 \mathrm{~cm}$ above the symphysis pubis. The descending limb of the manometer is connected to an outlet tube and drainage bag. The irrigant reservoir is suspended from a $1000 \mathrm{~g}$ spring balance. Cystometric data are derived by observing the behaviour of the column of fluid in the ascending limb of the $U$ tube. A chart of pressure against volume is then plotted by recording bladder pressure and input volume at intervals of one minute. Normally, bladder pressure rises only slightly during filling but there will be sudden transient rises in pressure during, for example, coughing or changing position. With a detrusor contraction the rise in pressure is more sustained and is often sufficient to drive the column of fluid over the top of the $U$ tube.

For multichannel cystometry a double lumen catheter (Portex) was used to fill the bladder and measure pressure. In addition, abdominal pressure was recorded via a catheter in the rectum. Electronic subtraction of abdominal from total bladder pressure gave a value for true detrusor pressure. The pressure together with input volume was recorded on an MX6 pen recorder (Ormed).

After the two types of cystometry had been completed the other urodynamic tests normally conducted in this unit were done. These were measurement of the urethral closure pressure profile, ${ }^{9}$ stress testing of the urethral closure mechanism with the fluid bridge test ${ }^{10}$ (these two tests are designed to detect incompetence of the urethral sphincter and genuine stress incontinence), measurement of urine flow, and a one hour test of urine loss. ${ }^{11}$ The results of these tests were available only to the person doing the multichannel cystometry.

One of us (JRS) conducted all the multichannel tests whereas single channel tests were conducted mainly by the ward nursing staff. The type of incontinence diagnosed by the first investigator was not conveyed to the second, and the recorded results were kept separate. At the end of the study the two sets of results were compared and analysed.

\section{Results}

There was agreement between the two methods in 93 cases and disagreement in seven (table I). In these seven women single channel cystometry showed unstable bladders, but this diagnosis was not confirmed by the multichannel tests.

In some women the extra information collected during full urodynamic testing improved the final diagnosis. For example, sphincter weakness was found in 15 of the 35 patients in whom unstable bladders were shown by both types of cystometry (table II); it was

TABLE I-Number of women in whom a stable or unstable bladder was diagnosed by single channel or multichannel cystometry, or both

\begin{tabular}{lccc}
\hline & \multicolumn{2}{c}{ Single channel cystometry } & Total \\
\cline { 2 - 3 } & Stable & Unstable & \\
\hline $\begin{array}{l}\text { Multichannel cystometry: } \\
\text { Stable } \\
\text { Unstable }\end{array}$ & 58 & 7 & 65 \\
\hline Total & 58 & 42 & 100 \\
\hline
\end{tabular}

TABLE II-Diagnoses made by two different methods in 100 women

\begin{tabular}{lcc}
\hline & $\begin{array}{c}\text { Full urodynamic } \\
\text { testing }\end{array}$ & $\begin{array}{c}\text { Single channel } \\
\text { cystometry }\end{array}$ \\
\hline $\begin{array}{l}\text { Detrusor instability } \\
\text { Mixed detrusor instability and genuine }\end{array}$ & 20 & 42 \\
$\begin{array}{l}\text { stress incontinence } \\
\text { Genuine stress incontinence }\end{array}$ & 15 & $55^{*}$ \\
Sensory urgency & 51 & 3 \\
Outlet obstruction & 3 & \\
No urodynamic abnormality detected & 7 & 100 \\
\hline Total & 100 & \\
\hline
\end{tabular}

*Inferred because bladder was stable and no other abnormality was found. not always found in patients with stable bladders. Fourteen of 65 women with stable bladders were found not to have sphincter weakness from measurements of the urethral closure pressure profile and fluid bridge testing; three of these 14 were identified as having sensory urgency (an overwhelming desire to void at a low bladder volume) and four as having minor obstruction of outflow. In seven no urodynamic abnormality was found even after the full range of tests.

\section{Discussion}

Hodgkinson et al used a single channel system to define dyssynergic detrusor dysfunction. ${ }^{1}$ Later, Jeffcoate and Francis ${ }^{12}$ and others used it extensively as a diagnostic tool in clinical practice. The work of Bates et al in 1970, however, showed the importance of differentiating between changes in abdominal and intrinsic detrusor pressures, ${ }^{4}$ and thereafter the multichannel apparatus became popular.

Recently there has been a revival of interest in single channel systems because the multichannel apparatus is expensive. Neale described how a central venous pressure line could be used as a simple bladder manometer ${ }^{13}$; Willington ${ }^{14}$ and Eastwood ${ }^{15}$ found single channel cystometry to be a useful method for investigating geriatric patients but neither compared it with multichannel systems.

In this study there was agreement regarding stability of the bladder in 93 of our 100 patients. In all those with unstable bladders (diagnosed by single channel cystometry in centres where multichannel cystometry is not available) it would have been appropriate to start anticholinergic treatment while referring the others for fuller urodynamic investigations to a specialist centre if necessary. The seven women wrongly identified as having unstable bladders would have received the wrong (conservative) treatment. No doubt they, and those patients with a mixed type of incontinence, would have failed to respond adequately and have been referred later for fuller investigations.

The value of fuller urodynamic investigations, including measurements of urethral pressure and urine loss, is underlined by the results shown in table II. Urethral deficiencies were identified in nearly half of the women with unstable bladders, and yet some of the women with stable bladders were not found to have identifiable urethral defects. Thus a small risk exists with single channel systems that surgical treatment may be carried out even when no abnormality has been objectively confirmed.

Stanton, in discussing urodynamic procedures for nonspecialist centres, did not recommend measurement of urethral pressure. ${ }^{16}$ We think that this measurement is important as it may prevent surgical treatment being done in patients in whom no disorder has been confirmed. Supplementing the information derived from single channel cystometry is possible without electronic recording apparatus. Visual confirmation of stress leakage on coughing is a useful guide to the diagnosis. Moreover, two new techniques have been developed: in one leakage of urine is measured by a pad test, ${ }^{11}$ which indicates the presence or absence of incontinence and shows its severity; in the other, the fluid bridge flow test, ${ }^{17}$ incompetence of the bladder neck is shown using only a simple catheter.

Considerable advantage will be obtained if treatment can be initiated after simple tests, especially if waiting lists for more comprehensive examinations are long or the patient cannot be easily moved. Some of these tests can be conducted by nursing staff, permitting much wider use of urodynamic testing than at present.

Single channel cystometry, which costs little, can provide the most important single piece of diagnostic information about an incontinent patient, allowing treatment to be started immediately in some cases. Simple urethral tests are also available to supplement cystometry. Together they can provide most of the information that would be obtained in a specialist urodynamic investigation centre. 
We wish to thank Sister $\mathrm{V}$ Singleton and the nursing staff on Minoprio Ward, Women's Hospital, Liverpool, for performing the single channel cystometries.

\section{References}

${ }^{1}$ Hodgkinson CP, Ayres MA, Drukker BH. Dyssynergic detrusor dysfunction in the apparently normal female. Am F Obstet Gynecol 1963; 87:717-30.

${ }^{2}$ Farrar DJ, Whiteside CG, Osborne JL, Turner-Warwick RT. A urodynamic analysis of micturition symptoms in the female. Surg Gynecol Obstet 1975;141:875-81.

${ }^{3}$ Stanton SL. Surgery of urinary incontinence. In: Stanton SL, ed. Clinics in obstetrics and gynaecology. London: Saunders, 1978:83-108.

4 Bates CP, Whiteside CG, Turner-Warwick R. Synchronous cine/pressure/ flow cystourethrography with special reference to stress and urge incontinence. $B r \mathcal{F}$ Urol 1970;42:714-23.

${ }^{5}$ Arnold EP, Webster JR, Loose $\mathrm{H}$, et al. Urodynamics of female incontinence: factors influencing the results of surgery. Am $\mathcal{f}$ Obstet Gynecol 1973;117:805-13.

- Mosso A, Pellacani P. Sur les fonctions de la vessie. Arch Ital Biol 1882; 1:97-128.

${ }^{7}$ International Continence Society. First report on the standardisation of terminology of lower urinary tract function. Brf Urol 1976;48:39-42.
8 International Continence Society. Second report on the standardisation of terminology of lower urinary tract function. $\mathrm{Br} \mathcal{F}$ Urol $1977 ; 49$ : 207-10.

${ }^{9}$ Brown MC, Wickham JEA. The urethral pressure profile. Br $\mathcal{f}$ Urol $1969 ; 41: 211-7$.

10 Sutherst JR, Brown MC. Detection of urethral incompetence in women using the fluid bridge test. Br $\mathcal{F}$ Urol 1980;52:138-42.

11 Sutherst JR, Brown MC, Shawer M. Assessing the severity of urinary incontinence in women by weighing perineal pads. Lancet 1981; 1128-30.

12 Jeffcoate TNA, Francis WJA. Urgency incontinence in the female. Am F Obstet Gynecol 1966;94:604-18.

${ }^{13}$ Neale R. Simple cystometry. Lancet $1977 ; \mathrm{ii}: 927$.

14 Willington FL. Therapeutic distension for bladder instability in the elderly. In: Proceedings of the VIII International Continence Society Meeting. Manchester: Pergamon Press, 1978:13-7.

${ }^{15}$ Eastwood HD. Incontinence: who can benefit from simple investigation ? Modern Geriatrics 1978;8:39-43.

16 Stanton SL. What is the place of urodynamic investigations in a district general hospital ? Br F Obstet Gynaecol 1983;90:97-9.

17 Shawer M, Brown M, Sutherst JR. Diagnosis of bladder neck incompetence without use of capital equipment. $\mathrm{Br}$ Med $\mathcal{f} 1981$;283:760-1.

(Accepted 29 March 1984)

\section{SHORT REPORTS}

\section{Raised intracranial pressure due to large intracranial xanthoma}

Xanthomas are common in hyperlipoproteinaemia and reflect extravascular deposition of cholesterol esters in foam cells and extracellular deposition of crystalline cholesterol in sites such as skin, tendons, and the arterial wall. We report the first case of a patient presenting with raised intracranial pressure secondary to a large intracranial xanthoma.

\section{Case report}

A 31 year old man presented with a two month history of progressively worsening tension headaches, nausea, and vomiting. Clinical examination showed bilateral papilloedema, nystagmus on right lateral gaze, and right sided deafness. Large tendon xanthomas were noted on both elbows, knees, and Achilles tendons, and planar xanthomas, which had been present for many years, were also found. Eruptive xanthomas were also noted on the buttocks.

Computed tomography showed dilated ventricles with mild hydrocephalus and a large space occupying lesion in the right middle and posterior fossae, which did not enhance with contrast. Right carotid and vertebral angiography confirmed a large avascular mass predominantly in the posterior fossa, with no evidence of a pathological circulation. In view of his rapidly deteriorating condition combined supratentorial and infratentorial craniotomy was performed at the National Hospital, Queen Square, and a large, predominantly extradural mass removed. Postoperatively he recovered completely; subsequent computed tomography confirmed that the hydrocephalus had resolved and that the lesion had been completely removed.

\section{PATHOLOGY REPORT}

Microscopically, the histological appearance was uniform, with large numbers of cholesterol clefts surrounded by foreign body giant cells. Particularly striking were the sheets of numerous foamy macrophages with small round nuclei. The edge of the lesion was present in many blocks, but no keratin, skin appendages, or epithelium were demonstrated in any of the sections. The histological diagnosis was an intracranial xanthoma.

Subsequently, hypercholesterolaemia was found on routine testing, and the patient was referred to the lipid clinic at this hospital for further assessment.

On presentation no residual neurological abnormalities were demonstrable. Repeated estimation of fasting lipid concentrations confirmed severe combined hyperlipidaemia with mean pretreatment concentrations of cholesterol 18 mmol/1 $(696 \mathrm{mg} / 100 \mathrm{ml})$ and triglycerides $10.0 \mathrm{mmol} / 1(886 \mathrm{mg} / 100 \mathrm{ml})$. Analysis of serum lipoproteins showed increased concentrations of both very low density and low density lipoproteins. ${ }^{1}$ Gradient density ultracentrifugation did not show any intermediate density lipoproteins. Analysis of apoproteins showed normal proportions of apo C-II and apo C-III isoforms and an apoprotein $E$ phenotype of $E_{3} / E_{4}$.

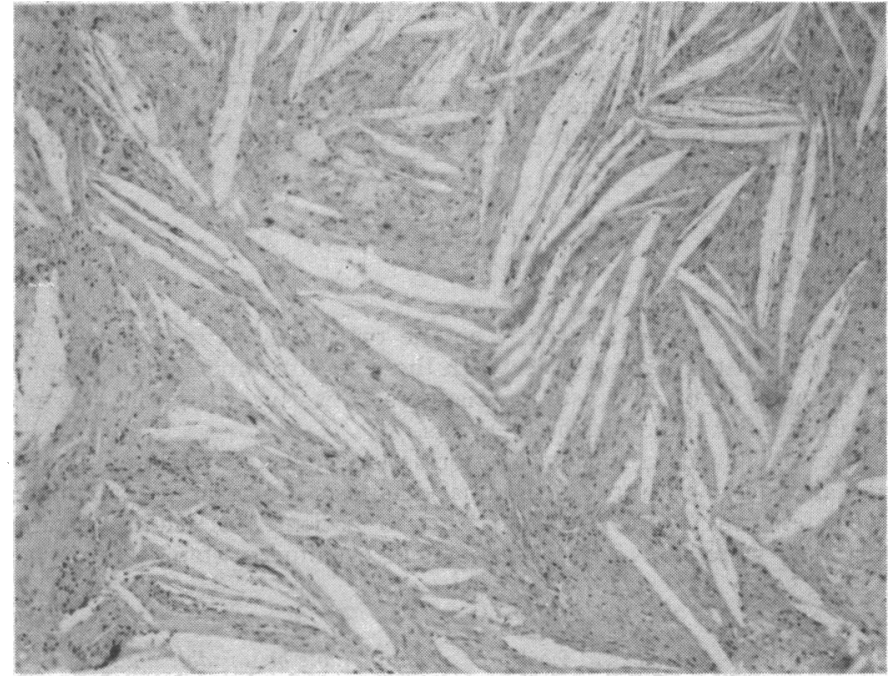

Numerous cholesterol clefts with intervening foam cells. Haematoxylin and eosin $\times 100$.

Family screening confirmed his mother to have severe combined hyperlipidaemia. His father had died aged 43 from chronic renal failure; his 30 year old sister was not affected. Of his two sons aged 3 and 4 , one had a raised serum cholesterol concentration $(8.5 \mathrm{mmol} / 1(329 \mathrm{mg} / 100 \mathrm{ml}))$ and the other a raised serum triglyceride concentration $(3.5 \mathrm{mmol} / 1(310 \mathrm{mg} / 100 \mathrm{ml}))$ Thus over the three generations the hyperlipidaemia was inherited in an autosomal dominant fashion.

Response to treatment was dramatic, persistent normolipidaemia being achieved by modifying the fat content of his diet and giving two sachets of cholestyramine and bezafibrate $200 \mathrm{mg}$ both thrice daily.

\section{Comment}

This appears to be a unique case. A case has been reported of familial type IIa hyperlipoproteinaemia associated with a huge intracranial xanthoma, ${ }^{2}$ but it was not the presenting feature. Our patient had severe combined familial hyperlipidaemia (World Health Organisation type IIb).

The possibility that intracranial xanthoma may recur in uncontrolled hyperlipidaemia is as important prognostically as the considerably increased risk of accelerated atherosclerosis; consequently, treatment to reduce the lipidaemia may obviate the need for such extreme measures as ileojejunal bypass surgery. 